\title{
Characterization of Embedded Root Method in UV-LIGA Process
}

\author{
Chien-Hung Ho, Wensyang Hsu* \\ Department of Mechanical Engineering, National Chiao Tung University, \\ 1001 Ta Hsueh Road, Hsinchu, Taiwan 30010, Republic of China
}

\begin{abstract}
SU-8 photoresist has been popularly used as a mold for electroplating and facilitated low-cost MEMS production in many previous researches. However, the reachable thickness of electroplated structures standing on the substrate were limited to $50 \mu \mathrm{m}$ below due to the internal stress and deformation of the SU-8 resist in final stripping process. In order to fabricate thicker structures, an embedded root method has been proposed to consolidate the adhesion of the metal structures to the substrate during the SU-8 removal process. In this paper, detailed investigation on this method is conducted to characterize the relationship among the root depth, the line-width and the allowable thickness of the electroplated structures. Some test patterns with embedded roots are designed and tested to generalize the possible extent of various structural scales associated with different niches in depth, which are completely defined through $\mathrm{SiO}_{2}$ masking and $\mathrm{KOH}$ etching processes. Based on establishment of the relationship between the root depth and the geometric sizes, a 3-D integrated coil with $200 \mu \mathrm{m}$ in thickness, $80 \mu \mathrm{m}$ in width and $4 \mu \mathrm{m}$ in root depth is successfully released by the SU-8 mold with $400 \mu \mathrm{m}$ in height, which can not be achieved by the standard SU-8 molding process. The UV-LIGA process presented herein may be applied to the fabrication of other microstructures and microactuators.
\end{abstract}

Keywords: Embedded root, SU-8, UV-LIGA, Electroplating

\section{INTRODUCTION}

A metal structure with a vertical sidewall and high aspect ratio can enhance the output force in microactuators, such as magnetic or electrostatic actuators. Also, this thicker structure will increase the toughness of the components and prevent the micro devices from cracking due to mechanical failure or stress concentration during long-term operation. In order to achieve that, the photoresist, NANO ${ }^{\mathrm{TM}}$ XP SU-8 (MicroChem Crop., (MCC)) announced by IBM has been served as a mold to electroform the required metal structures in MEMS production. ${ }^{1}$ On account of its superior optical transparency and contrast under near-UV light, several studies have been worked on the patterning of ultra-thick structures and molds with highly vertical profiles by using this photoresist. Presently, in a single layer spin coating, *Tel.: 8863-5712121-55111; Fax: 8863-5720634; e-mail: whsu@cc.nctu.edu.tw 
more than $500-\mu \mathrm{m}$-thick photoresist and an aspect ratio of 18 could be achieved reproducibly. ${ }^{2}$ To implement a metalized process of the microstructures, Lorenz et al. ${ }^{3}$ and Lee et al. ${ }^{4}$ attempted to fabricate various metal components, including microgears and microcoils, through the UV-LIGA technique with these resist molds.

Although over a 500- $\mu$ m-thick SU-8 mold may be realized, the thickness of the released electroplated structure standing on the substrate is rare to reach more than $50 \mu \mathrm{m} .{ }^{3-5}$ During the mold stripping process, since the SU-8 photoresist will swell and deform when it is immersed in the standard commercial remover provided by MCC. For thicker (>100 $\mu \mathrm{m})$ electroplated microstrcture, significant internal stress induced at the interface between the metal component and the mold results in the failure either to resist remnant or to structure ablation. In order to fabricate a thicker metal structure, which still adheres to the substrate after the mold removal, Ho et al. ${ }^{6}$ proposed an embedded root method to consolidate the binding of the electroplated microstructures with an underlayer, and also successfully applied this method to the fabrication of an UV-LIGA micromotor. ${ }^{7}$ However, no advanced researches have been done on the relationship between the root depth and the allowable height of the electroplated structures.

Here, detailed investigation on this method is conducted to characterize the relationship among the root depth, line-width and the reachable thickness of the electroplated structures. Some bar-shaped test structures with various geometric sizes are designed and fabricated, where the depth of a niche is defined by $\mathrm{KOH}$ etching processes and using $\mathrm{SiO}_{2}$ as a mask. The metal structure with embedded root inside of the wafer is then electroplated to reinforce structural adhesion and sustain internal stress in the follow-up SU-8 removal process. Subsequently, the reference data about limitation of the line-width and the thickness with different roots in depth are established. According to the experimental results between the root and the allowable electroplated thickness, a 3-D integrated coil with $200 \mu \mathrm{m}$ in thickness is completely released to demonstrate the feasibility and reliability of this reference data. Therefore, the result and information relevant to this study may be useful to those who are planning to upgrade the output force of magnetic or electrostatic actuators with an UV-LIGA process by the SU-8 photoresist.

\section{METHOD}

The removal of crosslinked SU-8 is the most difficult process among the serial UV-LIGA procedures with the resist. At present, an effective approach to normally dissolve a cured SU-8 mold as well as not to destroy other structural entities by wet etchant is still unavailable. Remover PG, which is provided from MCC, may remove the resist from the substrate by lift-off mechanism. However, during this stripping process the swell effect of SU-8 always generates extensively increased internal stress at the interface between the mold and the electroplated structure, resulting in the failure either to resist remnant or to structure ablation. An improved method for consolidating the adhesion of the microstructure to the substrate and for reducing the drag force induced on the sidewalls of SU-8 has been proposed. By constructing substructure with an embedded root, this novel technique can greatly promote the thickness of the metal components as well as increase the probability in making the SU-8 mold stripped completely. In this section, further studies based on the embedded root method are carried out to characterize the relationship in the size effect of 
the electroplated structure associated with the root construction. After the stripping of the SU-8 mold, smallest line-width or resolution, appropriate spaces between entities and allowable thickness of the successfully released microstructure versus its root depth are obtained through the experimental results. The experimental data is then referred to the design and fabrication of a 3-D integrated coil, which is several times thicker in height than a traditional planar coil with standard SU-8 molding process, to verify the feasibility of the test results.

\subsection{Process design}

The fabrication process of metal structures with embedded roots in this study is shown schematically in Fig. 1. First, a (100) silicon wafer is thermally grown to produce a thick silicon dioxide layer (Fig. 1(a)). Notably, this layer is used as a shield mask for later etching process to construct niches in the substrate. Following near-UV lithography, the insulation layer is patterned to expose the underlayer surface in the desired positions (Fig. 1(b)). The etched places are the locations of the embedded roots to be defined. Next, an anisotropic etching process with a $\mathrm{KOH}$ solution is utilized to form the niches for subsequent electrodeposition of the root structures (Fig. 1(c)). The required depth of the embedded roots inside of the substrate depends on the geometric size of the electroplated structures, which will be discussed in the section of the experimental results. To obtain conformal morphology of the root construction, first an adhesive titanium layer and then a copper seed layer are deposited via sputtering (Fig. 1(d)). This bi-layer is served as a conductive cathode in the electroplating processes. Then, SU-8 photoresist is spun over the seed layer via near-UV-lithographic technique (Fig. 1(e)). The resist layer is delineated to build thick molds with niches in the substrate. When immersed in Ni plating bath, this high-aspect-ratio mold is provided for electroplating desired metal entities with roots forming in the niches (Fig. 1(f)). The deposited thickness of the Ni during the electroplating proces s must be controlled adequately in order to reduce the internal stress generated between the structures and the mold. In the mold removal process, the Remover PG is offered to strip SU-8 polymer resin (Fig. 1(g)). With the roots embedded in the substrate and appropriate height control of the electroplated structures, the metal entities will adhere strongly to the substrate without ablation, while the crosslinked SU-8 mold can be removed completely.

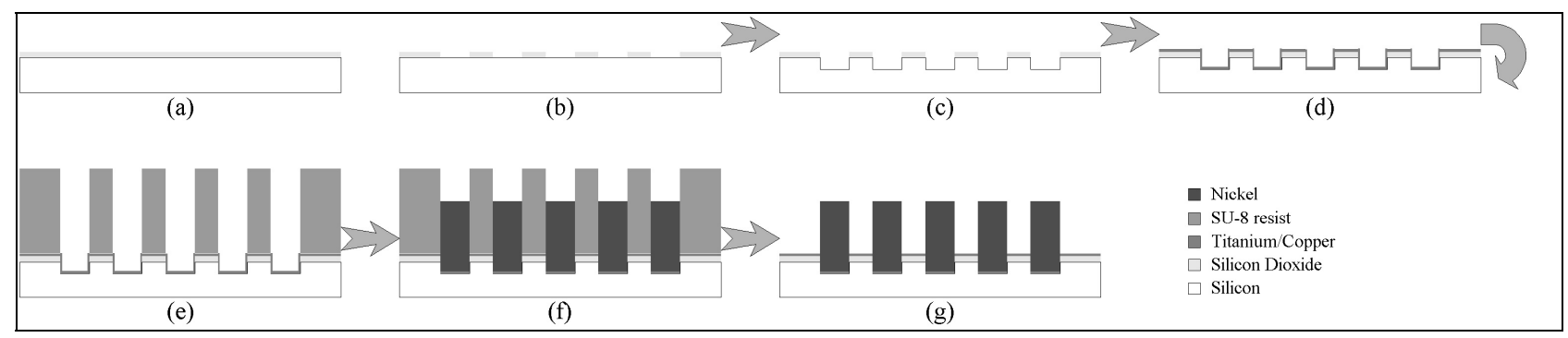

Figure 1: Fabrication processes of the UV-LIGA integrated coil with root construction. (a) Silicon dioxide layer formation. (b) Oxide delineation as mask layer. (c) Anisotropic etching in the silicon substrate. (d) Adhesion/seed layer sputtering. (e) Thick photoresist patterning, and mold building. (f) Metal structure electroplating. (g) Mold removal in the final release. 


\subsection{Parameter conditions}

Figure 2 shows a schematic diagram concerning the geometric arrangement of test structures. Symbol ' $r$ ' expresses the depth of an electroplated root that is deposited in the niche defined through $\mathrm{SiO}_{2}$ masking and $\mathrm{KOH}$ etching processes and symbol ' $h$ ' is the desired height (i.e. the thickness) of the entity in the electroplating fabrication. Symbols ' $w$ ' and ' $l$ ' denote the width (i.e. the line-width) and length of the metal entity, respectively, and symbol ' $s$ ' presents the space between two metal entities. The SU-8 mold thickness (symbol ' $m$ ', not shown here) is always kept at $300 \mu \mathrm{m}$ constantly in this study. To eliminate size effect, which may affect the validity of experimental results, the dimension of the pattern length $l$ is designed at least five times longer than that of the pattern width $w$. For different placements in line-width and space, the required root depth and allowable height of the metal entity will be evaluated to implement the characterization of the embedded root method.

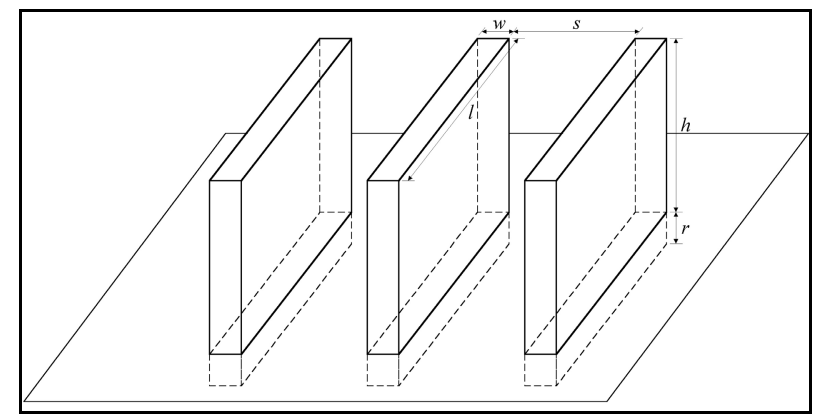

Figure 2: Schematic diagram of the geometric arrangement of test metal structures.

Table 1 displays the parameters in realizing the UV-LIGA process with SU-8 mold shown in Fig.1. The thick silicon dioxide layer is $1 \mu \mathrm{m}$ in thickness and needs an isotropic wet etching continuing about 10 minutes in the standard buffered oxide etchant (BOE). In the niche construction, 4- $\mu \mathrm{m}$-deep (i.e. $\mathrm{SiO}_{2}$ of $1 \mu \mathrm{m}+\mathrm{Si}$ of $3 \mu \mathrm{m}$ ), 7- $\mu \mathrm{m}$-deep (i.e. $\mathrm{SiO}_{2}$ of $1 \mu \mathrm{m}+\mathrm{Si}$ of $6 \mu \mathrm{m}$ ) or $10-\mu \mathrm{m}$-deep (i.e. $\mathrm{SiO}_{2}$ of $1 \mu \mathrm{m}+\mathrm{Si}$ of $9 \mu \mathrm{m}$ ) root depth are optionally fabricated by hot $\mathrm{KOH}$ etchant $\left(40 \%\right.$ in weight, $\left.80{ }^{\circ} \mathrm{C}\right)$. For the seed layer formation, Ti of $500 \AA$ is physically sputtered on the substrate first, and then a 5000- $\AA$-thick Cu layer is superposed on this Ti layer in the same chamber.

Table 1: Parameter conditions of UV-LIGA process with SU-8 mold.

\begin{tabular}{|l|l|l||}
\hline Process Step & Parameters & Equipment and Chemical Solvent \\
\hline Thermally wet Oxidation & $1 \mu \mathrm{m}$ in thickness, $1050{ }^{\circ} \mathrm{C}$ for $3.2 \mathrm{hrs}$ & Quartz Furnace \\
\hline $\mathrm{SiO}_{2}$ Lithography & Standard Recipe & FH 6400 \\
\hline $\mathrm{SiO}_{2}$ Wet Etching & 12 min immersion & Buffered Oxide Etchant $(\mathrm{BOE})$ \\
\hline \multirow{3}{*}{ Anisotropic Etching } & $\begin{array}{l}\text { Roots of } 4,7 \text { or } 10 \mu \mathrm{m} \text { in depth } \\
40 \% \text { in weight, } 80{ }^{\circ} \mathrm{C} \\
0.3 \mu \mathrm{m} / \mathrm{min} \text { in etching rate }\end{array}$ & Potassium Hydroxide $(\mathrm{KOH})$ \\
\hline Seed Layer Deposition & $\begin{array}{l}\mathrm{Ti} 500 \AA .0 .23 \AA / \mathrm{min} \\
\mathrm{Cu} 5000 \AA, 1.2 \AA / \mathrm{min}\end{array}$ & Physical Sputter \\
\hline
\end{tabular}


Table 2 specifically summarizes the process parameters and the related equipment to create the $300-\mu \mathrm{m}$-thick SU- 8 mold. Although SU-8 photoresist has been widely employed in MEMS, recommended operational parameters differ from one another in these published references. As the SU-8 coating technique is yet not standardized, the particularly conditional data depends not only on the local experimental equipment, but also on the structure geometry.

Table 2: Process Conditions of NANO ${ }^{\mathrm{TM}}$ XP SU-8 50 for $300 \mu \mathrm{m}$ in height.

\begin{tabular}{|c|c|c|}
\hline Process Step & Parameters & Equipment and Chemical Solvent \\
\hline Dehydration Bake & $150{ }^{\circ} \mathrm{C}$ for $15-20 \mathrm{~min}$ & $\begin{array}{l}\text { Vacuum Oven } \\
\text { No HMDS Priming } \\
\end{array}$ \\
\hline Spin Coating & $\begin{array}{l}\text { Spread: } 300 \mathrm{rpm} \text { for } 25 \mathrm{sec} \\
\text { Spin: } 500 \mathrm{rpm} \text { for } 45 \mathrm{sec} \\
\text { Acceleration: } 100 \mathrm{rpm} / \mathrm{sec}\end{array}$ & $\begin{array}{l}\text { Karl Suss } \\
\text { GYRSET RC8 (Open) }\end{array}$ \\
\hline Relaxation & $0.5-1 \mathrm{~min}$ & \\
\hline Mass Measure & $3.1-3.3 \mathrm{~g}$ & Precision Balance \\
\hline Soft Bake & $90{ }^{\circ} \mathrm{C}$ for $10 \mathrm{hrs}$ & Hotplate \\
\hline Relaxation & $8 \mathrm{hrs}$ & \\
\hline Exposure & Dose: $1350 \mathrm{~mJ} / \mathrm{cm}^{3}$ & $\begin{array}{l}\text { Karl Suss MJB3 } \\
\text { Broad Band Near UV }\end{array}$ \\
\hline Post Exposure Bake & $90^{\circ} \mathrm{C}$ for $20 \mathrm{~min}$ & Hotplate \\
\hline Relaxation & $24 \mathrm{hrs}$ & \\
\hline Development & 20 min immersion & $\begin{array}{l}\text { PGMEA from MCC } \\
\text { Ultrasonic Cleaner (Optional) } \\
\end{array}$ \\
\hline Removal & $70^{\circ} \mathrm{C}$ for $12 \mathrm{hrs}$ & $\begin{array}{l}\text { Hot REMOVER PG from MCC } \\
\text { Hotplate } \\
\text { Ultrasonic Cleaner (Optional) }\end{array}$ \\
\hline
\end{tabular}

Following the niche construction and SU-8 mold preparation, samples are electroplated in a nickel-sulfamate-based solution. The bath condition, including compositions, $\mathrm{pH}$ and operational temperature, can be referred to Table 3 .

Table 3: Process Conditions of Ni electroplating bath.

\begin{tabular}{|lr|lr||}
\hline \multicolumn{2}{|c|}{ Composition } & \multicolumn{2}{c|}{ Operational condition } \\
\hline \hline $\mathrm{Ni}_{\left(\mathrm{NH}_{2} \mathrm{SO}_{3}\right)_{2} \cdot 4 \mathrm{H}_{2} \mathrm{O}}$ & $450 \mathrm{~g} / \mathrm{l}$ & pH value & 4.6 \\
$\mathrm{NiCl}_{2} \cdot 6 \mathrm{H}_{2} \mathrm{O}$ & $3 \mathrm{~g} / \mathrm{l}$ & Temperature & $43{ }^{\circ} \mathrm{C}$ \\
$\mathrm{H}_{3} \mathrm{BO}_{3}$ & $35 \mathrm{~g} / \mathrm{l}$ & Current density & $1 \mathrm{~A} / \mathrm{dm}^{2}$ \\
Wetting and leveling agent & a little & Flow of jet agitation & $7 \mathrm{l} / \mathrm{m}$ \\
\hline
\end{tabular}

\section{RESULTS AND DISCUSSION}

This section presents the key results with respect to the characteristic investigation of the embedded root method in an UV-LIGA process. Some photographs of test microstructures, comprising SU-8 resist molds before electrodeposition and electroplated metal entities after the mold removal process, are illustrated and discussed. The collected data 
pertaining to the relationship between geometric features and root structures are formulated with related charts. These diagrams also exhibit a limitation of reachable thickness of the electroplated microstructures with various root depths. Based on the established relationship, an integrated coil with high aspect ratio is successfully fabricated, which can not be achieved by the standard SU-8 molding process.

\subsection{SU-8 mold formation}

Figure 3(a) shows a scanning electron micrograph (SEM) of the molds of bar-shaped test structures created with SU-8 photoresist. In this study, the resist mold is restricted at a given thickness of $300 \mu \mathrm{m}$ (i.e. $m=300 \mu \mathrm{m}$ ) through the whole experiment. By using lithographic parameters listed in Table 2, the SU-8 structure with the best resolution of 20 $\mu \mathrm{m}$, and an aspect ratio of 15 is achieved, where this resist width is also the space $s$ between metal entities, as shown in Fig. 2. However, by the given parameters, the best resolution of the SU-8 mold that is expressed as $w$ is $40 \mu \mathrm{m}$. For smaller line-width $w$, developer is hard to flow into the deep trench of the mold to completely clean the unexposed and uncrosslinked SU-8 resist. Therefore, Ni metal is rarely deposited on the conductive $\mathrm{Ti} / \mathrm{Cu}$ seed layer in later electroplating process. Figure 3(b) exhibits the metal structures that are successfully electroplated in the mold of 40 $\mu \mathrm{m}$ in width $w$ and also stand well on the substrate after final mold release process.

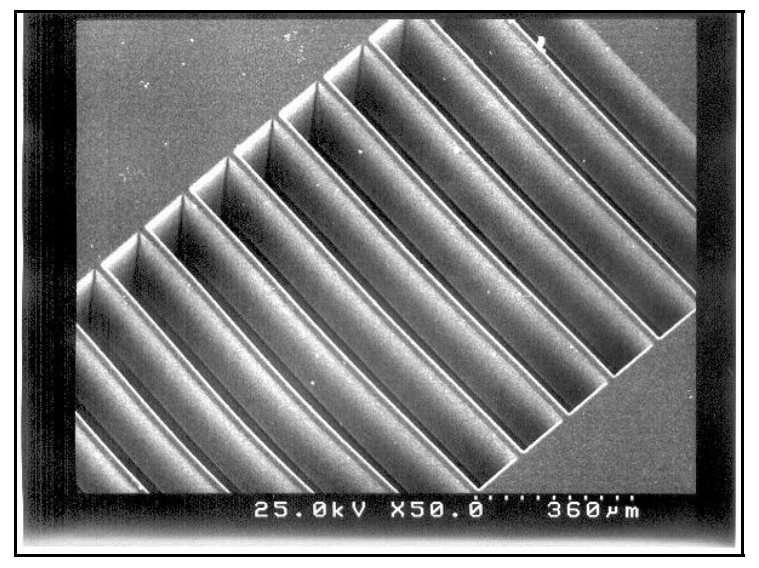

(a)

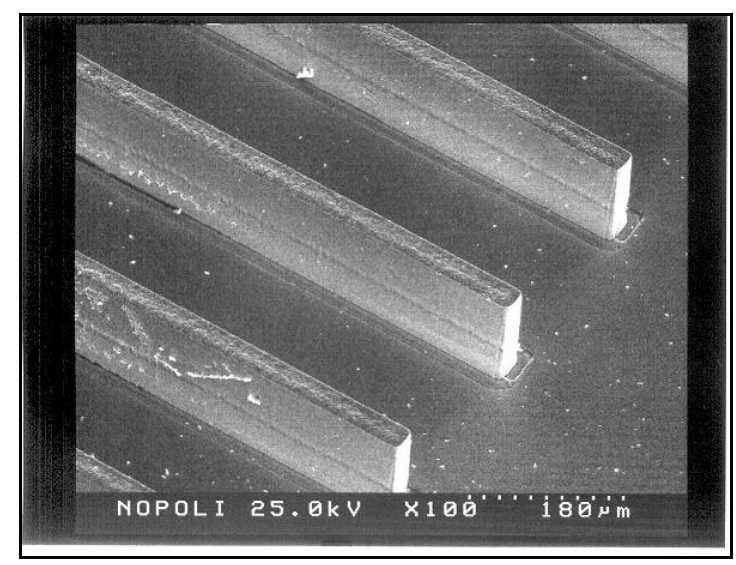

(b)

Figure 3: Achievable best resolution of SU-8 by process conditions in Table 2. (a) SU-8 molds of $20 \mu \mathrm{m}$ in resist space $s$. (b) Ni structures of $40 \mu \mathrm{m}$ in line-width $w$.

\subsection{Structures without embedded roots}

Figure 4 displays an exemplary illustration regarding the difficult problem occurring when the crosslinked SU-8 mold is immersed in the hot remover for stripping process. Before electroplating, a mold of $40 \mu \mathrm{m}$ in space $s, 80 \mu \mathrm{m}$ in width $w$ and $300 \mu \mathrm{m}$ in height $h$ is previously exhibited in Fig. 4(a). After the electroplating, the sample without embedded root construction is proceeded to strip the mold by the remover. Apparently, for higher electroplated structures, segments of the photoresist remain on the substrate, particularly in the clearance between two entities (Fig. 4(b)). This 
phenomenon may be caused by the accumulated internal stress, which is induced among the junctions of the seed layer, the Ni structure, and the polymerized resist during the fabrication processes, such as lithography, electroplating, and mold removal. Figure 4(c) presents another case that often appears when hot remover is employed to clean the crosslinked SU-8. Since the adhesion at the $\mathrm{Ni} / \mathrm{Cu}$ interface can not withstand the lift force, some electroplated metal structures are also detached from the substrate when the mold is heaved in the remover.

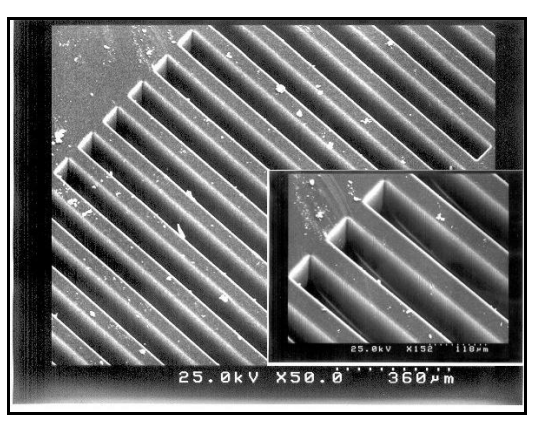

(a)

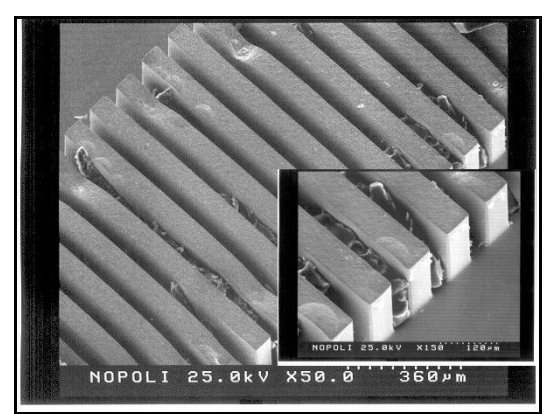

(b)

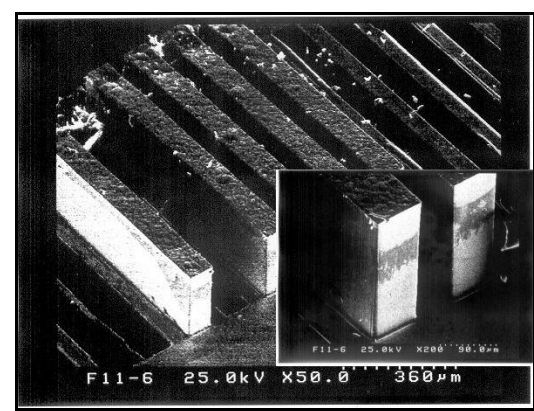

(c)

Figure 4: SEM of SU-8 stripping via hot remover without embedded roots. (a) Molds before electroplating. (b) SU-8 remnants after mold stripping. (c) SU-8 removal accompanied metal structure ablation.

\subsection{Structures with embedded roots}

There are two key techniques to construct the electroplated structures while using SU8, including the embedded root method and the height control in electroplating. During the SU-8 stripping process, swelling and deformation of the photoresist induce significant stress on the electroplated structures. With roots embedded in the substrate, the electroplated structures become stronger to withstand the stress from the swelling SU-8 resist. On the other hand, when the height of the electroplated structure is scaled down, the contact area between the photoresist mold and electroplated structure also becomes smaller. Then, the net clamping force on the mold can be effectively reduced, which results in successful removal of the SU-8 resist in the lift-off process by Remover PG.

With the same size of SU-8 mold shown in Fig. 4(a), successfully released structures standing on the substrate are presented in Fig. 5. Figure 5(a) shows the electroplated entities with $160 \mu \mathrm{m}$ in height, $80 \mu \mathrm{m}$ in width and 7- $\mu \mathrm{m}$-deep roots inside of the substrate. By the root construction, the metal structures can endure the internal stress from the swelling photoresist during the mold stripping with hot remover. Additionally, an ultrasonic vibration is also utilized to assist this removal process. Figure 5(b) illustrates the electroplated structures with $120 \mu \mathrm{m}$ in height, $80 \mu \mathrm{m}$ in width and 1- $\mu \mathrm{m}$-deep roots inside of the substrate. A reduction in the electroplated thickness (e.g. 120- $\mu$ m-thick structures for $300-\mu \mathrm{m}$-thick molds in this example) is beneficial to the decrement of the stressed force on the sidewalls of SU-8. Therefore, only an embedded root of $1 \mu \mathrm{m}$ is sufficient to completely strip the crosslinked photoresist as well. 


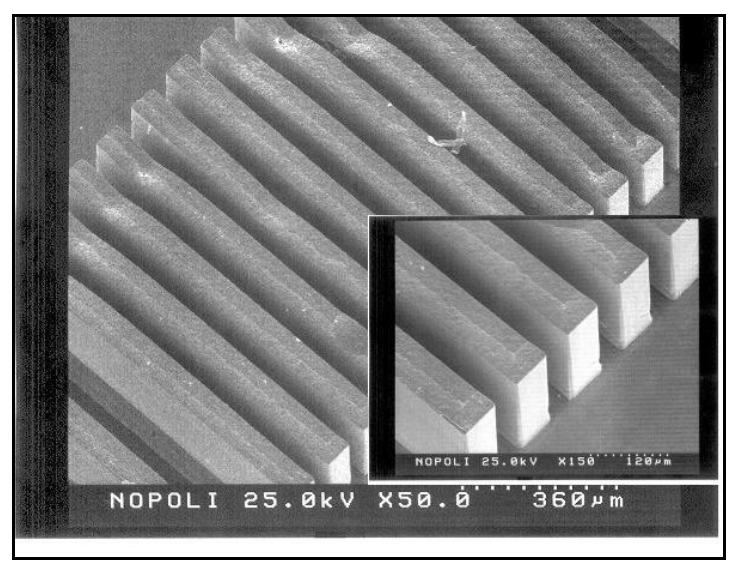

(a)

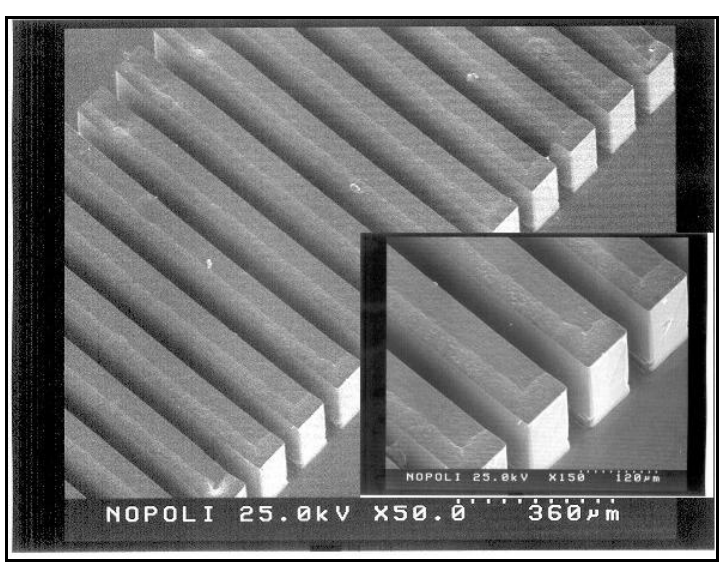

(b)

Figure 5: Successfully released structures standing on the substrate. (a) Structures with deep embedded roots (160 $\mu \mathrm{m}$ in structure height, 7- $\mu \mathrm{m}$-deep roots). (b) Height control in electroplated structures (120 $\mu \mathrm{m}$ in structure height, 1- $\mu \mathrm{m}$-deep roots).

\subsection{Relationship between root depth and geometric dimensions}

Figure 6 summaries the experimental results of the relationship among the root depth $r$, the line-width $w$, the space $r$ and the allowable thickness of the electroplated structure $h$. In this investigation, the thickness of the SU-8 mold $m$ is constant at $300 \mu \mathrm{m}$ and the electroplated structures are changed from 240, 200, 160 to $120 \mu \mathrm{m}$ in height, as shown in Fig. 6(a)-6(d), respectively.

For thicker metal structures, where $h$ is $240 \mu \mathrm{m}$ and the ratio of $h$ to $m$ is 0.8 as illustrated in Fig. 6(a), the crosslinked SU-8 is very difficult to remove with hot remover and even an ultrasonic vibration. The stripping process chiefly fails in residual resist wedged into the gaps between the structures. The smallest line-width falls on $120 \mu \mathrm{m}$ for the space of $200 \mu \mathrm{m}$ and $4 \mu \mathrm{m}$ in root depth. Therefore, the trade-off between line-width and space at thick structures are evident. Figure 6(b) and Figure 6(c) show a crucial distinction among the space, the line-width and the root depth. In the case of structures with $200 \mu \mathrm{m}$ in height, various scales in space produce much more difference in the smallest line-width of the metal entities (Fig. 6(b)). As shown on line E (i.e. $40 \mu \mathrm{m}$ in space) in Fig. 6(b), a reason for the slight increase in line-width with the root depth may be the mask misalignment of the SU-8 mold with the underlayer, which causes the resist harder to strip on the flat surface than on the niches of the substrate. On the other hand, for $h / m=0.53$ ( $h=160$ $\mu \mathrm{m})$ in Fig. 6(c), there is much variance at the root of $4 \mu \mathrm{m}$ below in depth. For example, the line-width reaches 2.5 times smaller on $4-\mu \mathrm{m}$-deep root than on $0-\mu \mathrm{m}$-deep one with space of $80 \mu \mathrm{m}$ (i.e. line D) in Fig. 6(c).

Figure 6(d) indicates the characterization of the embedded root method with the electroplated height of $120 \mu \mathrm{m}$. With the lower structural thickness $(h / m=0.4$ ), the root depth just needs to be $1 \mu \mathrm{m}$ and the smallest line-width for different spaces can be achieved at around 40 to $60 \mu \mathrm{m}$. This means that for $h \leq 120 \mu \mathrm{m}, \mathrm{s} \geq 60 \mu \mathrm{m}$ and $\mathrm{m}=300 \mu \mathrm{m}$, an $1-\mu \mathrm{m}$-deep root is sufficient to withstand the internal stress induced during the SU-8 mold stripping process. 


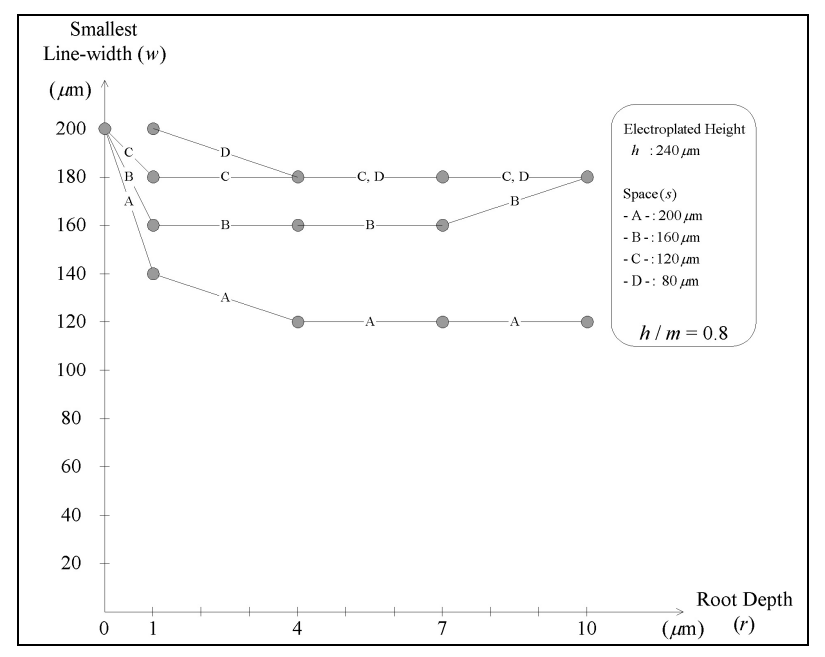

(a)

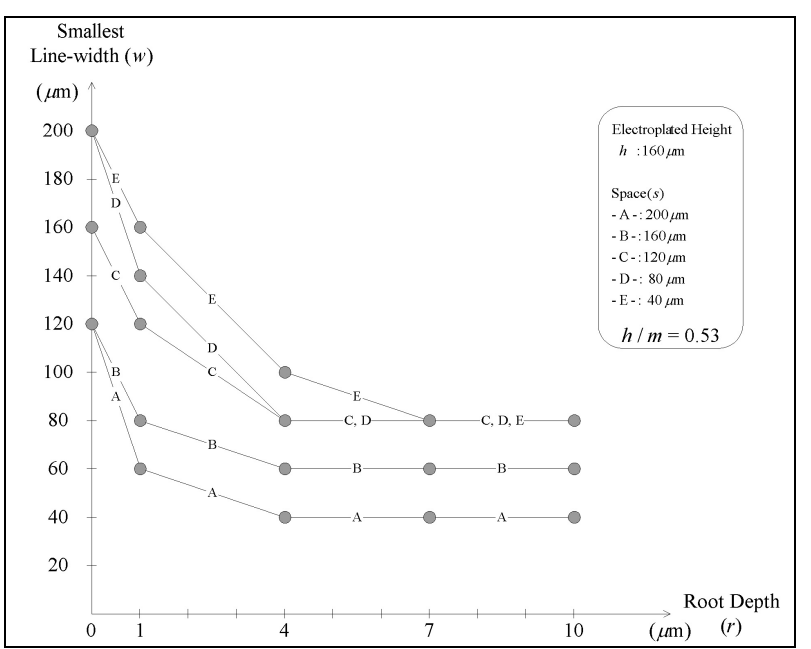

(c)

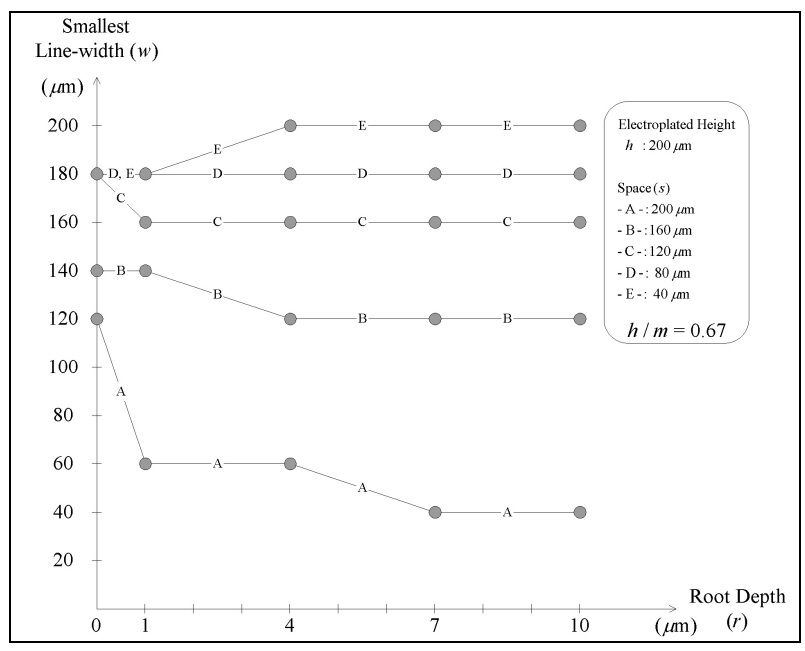

(b)

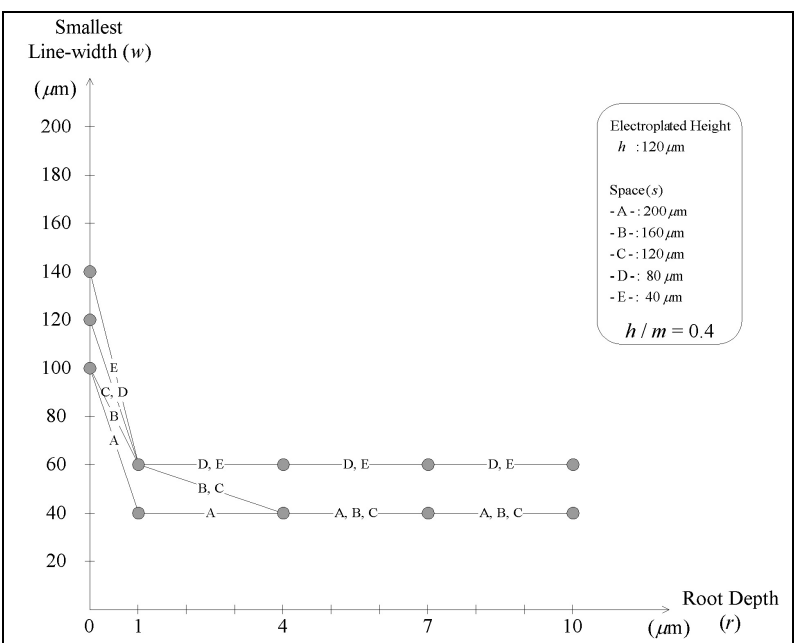

(d)

Figure 6: Relationship among the root depth $r$, the line-width $w$, the space $r$ and the allowable thickness of the electroplated structures $h$.

\subsection{Ratio of electroplated height to mold thickness}

In this subsection, a concept concerning the ratio of the electroplated height $h$ to the mold thickness $m$ is introduced to apply the characteristic data in Fig. 6 to different mold thickness and structural height. In Fig. 7, a comparison of integrated coils is shown where one is successfully released by the embedded root method (Fig. 7(c)) and the others fail due to photoresist residue and structure ablation (Fig. 7(a) and Fig. 7(b)). It is found that the SU-8 mold with $400 \mu \mathrm{m}$ in thickness $m$ and $80 \mu \mathrm{m}$ in width $s$ can be electroplated with an integrated coil with $200 \mu \mathrm{m}$ in height $h, 80 \mu \mathrm{m}$ in line-width $w$ and $4 \mu \mathrm{m}$ in root depth $r$. The ratio of $h / m$ equals 0.5 which corresponds to the criterion on line $\mathrm{D}$ (i.e. $80 \mu \mathrm{m}$ in space) in Fig. 6(c). 


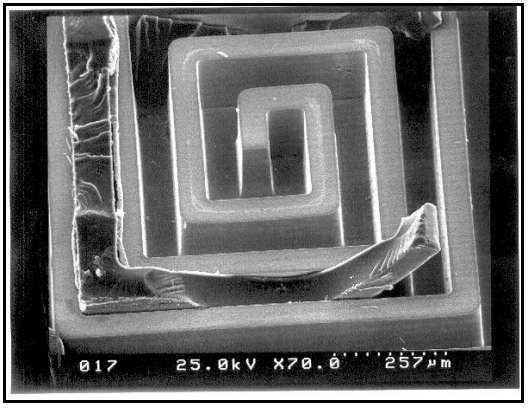

(a)

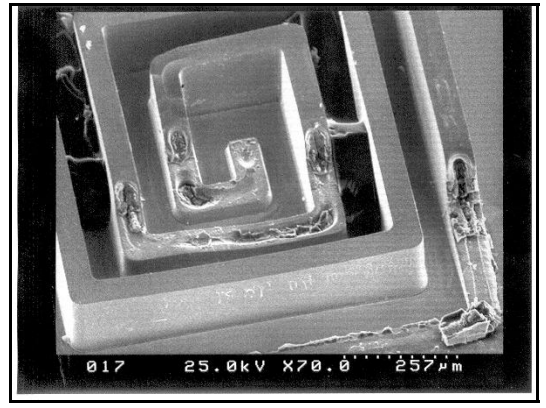

(b)

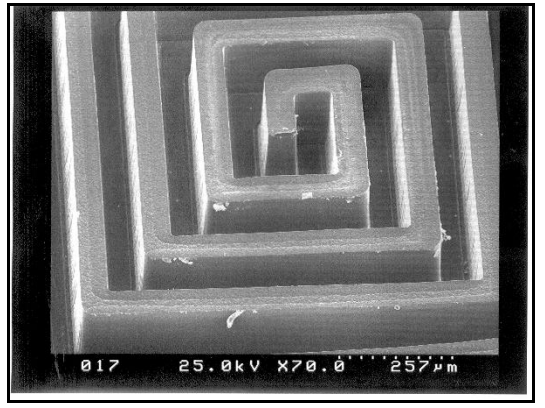

(c)

Figure 7: Comparison in the fabrication of integrated coil based on ratio of electroplated height $h$ to mold thickness $m$. (a) Photoresist residue. (b) Structure ablation. (c) Successful release according to the ratio of $h$ to $m$.

\section{CONCLUSIONS}

In this paper, characteristic study of an embedded root method is established to provide useful and reliable reference data for an UV-LIGA process with SU-8 photoresist. Some test structures have been fabricated to investigate the relationship among the root depth, the line-width and the possible thickness of electroplated structures. Various scales of niche depth are completely defined through $\mathrm{SiO}_{2}$ masking and $\mathrm{KOH}$ etching processes. The metal structure with embedded root inside of the substrate is then electroplated to reinforce structural adhesion and resist internal stress in the subsequent SU-8 removal process. By this reference data, an integrated coil with the embedded root can be successfully released according to a given ratio of the electroplated height to the mold thickness. The electroplated integrated coil with at least $200 \mu \mathrm{m}$ in thickness, $80 \mu \mathrm{m}$ in width and $4 \mu \mathrm{m}$ in root depth can be achieved by the SU-8 mold with $400 \mu \mathrm{m}$ in thickness, and the traditional standard method can fabricate the same integrated coil only about 50 $\mu \mathrm{m}$ in thickness. The techniques outlined herein may solve the notorious problem of the hard-to-strip polymerized SU-8 resist and assist the fabrication of other microstructures with similar needs by the UV -LIGA process.

\section{REFERENCES}

1. IBM Corp., US Patent No. 4882 245, 1989.

2. H. Lorenz, M. Laudon, P. Renaud, "Mechanical characterization of a new high-aspect-ratio near UV-photoresist", Microelectronic Engineering, (41/42) (1998) 371-374.

3. H. Lorentz, M. Despont, N. Fahrni, N. LaBianca, P. Renaud, P. Vettiger, "SU-8: a low-cost negative resist for MEMS", J. Micromech. Microeng. 7 (1997) 121-124.

4. M. Despont, H. Lorenz, N. Fahrni, J. Brugger, P. Renaud, P. Vettiger, "High -aspect-ratio, ultrathick, negative-tone near-UV photoresist for MEMS applications", IEEE Micro Electro Mechanical Systems Workshop, Jan. 1997, pp. 
518-522.

5. H.-K. Chang, Y.-K. Kim, "UV-LIGA process for high aspect ratio structure using stress barrier and C-shaped etch hole", Sens. Actuators A 84 (2000) 342-350.

6. C.-H. Ho, K.-P. Chin, "A novel embedded root method to construct thick metal microstructures using SU-8 in UV-LIGA process", 2002 ASME International Mechanical Engineering Congress and Exposition, New Orleans, Louisiana, USA, November 17-22, 2002.

7. C.-H. Ho, K.-P. Chin, C.-R. Yang, H.-M. Wu, and S.-L. Chen, "Ultrathick SU-8 mold formation and removal, and its application to the fabrication of LIGA-like micromotors with embedded roots", Sensor \& Actuators A, vol. 102/1-2 pp. 130-138, DEC/2002. 